Brit. J. industr. Med., 1965, 22, 72.

\title{
MORTALITY OF COAL-MINERS FROM CARCINOMA OF THE LUNG
}

\author{
BY \\ K. P. GOLDMAN* \\ From Sully Hospital, Glamorgan, South Wales
}

(RECEIVED FOR PUBLICATION AUGUST 4, 1964)

The results are presented from an investigation into the mortality of miners and ex-miners employed by the National Coal Board, from a comprehensive survey of respiratory disease in a Welsh mining community, and from a study of the comparative mortality from lung cancer in Welsh mining and non-mining towns. These results, together with previously published data which have been reviewed, show that in Great Britain the death rate of coal-miners from cancer of the lung is appreciably lower than the national rate for men of comparable age.

This occupational trend is not explicable by any of the factors which are known to influence the prevalence of the disease in the general population. In particular there is much evidence that the cigarette consumption of miners at least equals that of men in other occupations. The exclusion of this and other recognized aetiological factors suggests that the reduced mortality of miners from this disease is a specific effect of their occupation.

This effect might be a consequence of the inhalation of coal-dust, for there is some evidence that the incidence of death from lung cancer is lowest among miners whose exposure to coal-dust has been greatest.

The recorded mortality from cancer of the lung is appreciably lower for coal-miners than for other men of similar age. The purpose of this paper is to review the data on which this statement is based, to present supporting evidence from previously unpublished material, and to seek aetiological factors which might explain this occupational trend.

Kennaway and Kennaway (1936) examined the death certificates of men aged 20 years and over who had died in England and Wales during 1921-32 of cancer of the lung and larynx. Taking the population at risk as estimated at the national census they calculated age-standardized death rates for 63 occupations and noted especially low rates in agricultural workers and coal-miners. Thus for every 100 deaths from lung cancer expected in miners if the national rate had obtained, only 55 were registered. A later extension of this study covered the years 1933-38 and showed that for every 100 expected miners' deaths from this cause only 65 were registered (Kennaway and Kennaway, 1947).

Corroboratory data are contained in the Registrar General's Decennial Supplement on Occupational

*Present address: Brompton Hospital, London, S.W.3.
Mortality (1958), in which it is stated that in England and Wales in 1949-53 the standardized mortality ratio (S.M.R.) of mineworkers and quarrymen aged 20 to 65 for cancer of the lung was 71 . For the same period in Scotland the corresponding S.M.R. for coal-miners aged 15 to 64 was 80 (Registrar General for Scotland, 1956). These low ratios were not recorded for most other types of cancer, and during the same five-year period the Registrar General found the S.M.R. for cancer at all sites in the body to be almost the same in miners (S.M.R. $=95$ ) as the national average for men; the low ratio for lung cancer contrasted with a high ratio $($ S.M.R. $=149)$ for cancer of the stomach.

Evidence concerning the frequency of lung cancer among coal-miners was acquired by Doll (1958) incidental to an investigation of mortality in nickel workers. Data were obtained from the records of medical officers of health concerning the deaths of over 15,000 men who had been resident in four districts of South Wales during 1948-56. The ratio of deaths from lung cancer to deaths from other causes was calculated for several occupational groups and found to be particularly low for coalminers. If lung cancer had accounted for the same 
proportion of all deaths in coal-miners as it did in other men, then 152 miners' deaths from lung cancer would have been expected, whereas only 73 were recorded, a deficit of $52 \%$.

This comparatively low proportion of deaths from lung cancer might have resulted from a relatively high mortality from other causes, such as is known to occur among the miners of South Wales. However, Doll considered that after allowance for this factor there remained strong evidence of an unusually low mortality from lung cancer among these men, which was in contrast to the main finding of the study, namely of an unusually high mortality from this cause among nickel workers.

An analysis of death certificate data according to the type of mining job indicates that mortality from lung cancer is not as low for coal-face workers as for other miners. Thus in 1930-32 the age-standardized death rate for coal hewers and getters aged 20 to 65 was 67 compared with 36 for other underground workers and 100 for all men in England and Wales (Registrar General, 1938). Similarly in 1937-46 in five of the seven main coalfields, the recorded mortality from lung cancer was higher for coal-face workers than for other miners (Kennaway and Kennaway, 1953). During 1949-53 coal-face workers were again reported to have the highest death rate from this cause (S.M.R. = 87), with appreciably lower rates for other underground workers (S.M.R. $=61)$ and surface workers (S.M.R. $=64)($ Registrar General, 1958).

It has been suggested that regional variations of death rates from lung cancer and pneumoconiosis show a reciprocal relation between the frequency of the two diseases. Thus Kennaway and Kennaway (1953) noted a particularly low mortality from lung cancer among miners from the south-west coalfields, including South Wales, the area with the highest incidence of pneumoconiosis. However, an analysis of the Registrar General's regional mortality data for 1949-53 reveals no consistent relation between the frequency of the two diseases (Table 1). The S.M.R. for lung cancer was low in miners from

TABLE 1

STANDARDIZED MORTALITY RATIOS IN MINING AND QUARRYING OCCUPATIONS IN COALFIELDS IN ENGLAND AND WALES, 1949-53, OF MEN AGED 20 TO 64 (from the Registrar General, 1958)

\begin{tabular}{l|c|c}
\hline \multicolumn{1}{c|}{ Region } & $\begin{array}{c}\text { Lung Cancer } \\
\text { (S.M.R.) }\end{array}$ & $\begin{array}{c}\text { Pneumoconiosis } \\
\text { (S.M.R.) }\end{array}$ \\
\hline Glamorgan (anthracite) & 64 & $\infty$ \\
Glamorgan (other) & 75 & 4,814 \\
Monmouthshire & 57 & 1,875 \\
Durham & 72 & 527 \\
West Riding, Yorks & 66 & 338 \\
Cheshire and Lancs & 72 & 880 \\
North Staffs & 106 & 1,750 \\
South Staffs, Shrops, Worcs. & 75 & 1,367 \\
\hline
\end{tabular}

Glamorgan and Monmouthshire, areas where pneumoconiosis is most common, but was equally low in miners from the West Riding and Durham, where pneumoconiosis is comparatively rare.

The reported necropsy incidence of lung cancer in coal-miners is unusually low. At all the necropsies performed on men in three general hospitals in London and Leeds in 1945-48, lung cancer was found in $6.2 \%$ (Doll, 1953). By contrast, out of 592 necropsies which Gooding and colleagues performed on South Wales miners there was lung cancer in only $0.5 \%$, and of 300 necropsies on miners with pneumoconiosis McVittie found lung cancer in $1.3 \%$ (Gooding, 1946; McVittie, 1949). However, in neither study was a control series of non-miners available for comparison.

Chatgidakis (1963) reviewed the results of 1,010 necropsies performed on South African Bantu coalminers; the cause of death was specified in 759 , of which lung cancer was found in $0.5 \%$. However, many of these miners did not survive to the age at which lung cancer becomes most common; $45 \%$ died before reaching 40 , which suggests that the low rate was partly a consequence of competing causes of death.

A more critical study was that by James, who compared the results of necropsies on 1,827 coalminers and 1,531 male non-miners of similar age from South Wales. Lung cancer was present in 3.3\% of the miners and in $5.4 \%$ of the non-miners (James, 1955). Of miners with simple pneumoconiosis, a tumour was found in $5.1 \%$ compared with $1.4 \%$ with progressive massive fibrosis. The author suggested that pneumoconiosis as a competing cause of death may have contributed to the low necropsy incidence of lung cancer among these workers.

\section{National Coal Board Enquiry}

During the course of an investigation into the accuracy of the Registrar General's occupational mortality data (Heasman, Liddell, and Reid, 1958) information was obtained, but not published, about the mortality of coal-miners from lung cancer. Professor A. L. Cochrane drew the author's attention to this work and permission has been obtained to report it (D. D. Reid, 1962, personal communication).

Data were acquired through the National Coal Board and local enquiries about miners and exminers aged 20 to 65 . It was calculated that for these men during 1955 the S.M.R. for lung cancer was 74, a figure similar to that reported by the Registrar General for 1949-53. However, in contrast to the Registrar General, Reid found a higher mortality from lung cancer in surface workers (S.M.R. = 
TABLE 2

STANDARDIZED MORTALITY RATIOS OF MINERS AND EX-MINERS EMPLOYED BY THE NATIONAL COAL BOARD, FOR CANCER OF THE LUNG AND FOR OTHER NEOPLASMS, 1955*

\begin{tabular}{l|c|c|c|c}
\hline & \multicolumn{2}{|c|}{$\begin{array}{c}\text { Underground } \\
\text { Workers }\end{array}$} & \multicolumn{2}{|c}{$\begin{array}{c}\text { Surface } \\
\text { Workers }\end{array}$} \\
\cline { 2 - 4 } & $\begin{array}{c}\text { Lung } \\
\text { Cancer }\end{array}$ & $\begin{array}{c}\text { Other } \\
\text { Neo- } \\
\text { plasms }\end{array}$ & $\begin{array}{c}\text { Lung } \\
\text { Cancer }\end{array}$ & $\begin{array}{c}\text { Other } \\
\text { Neo- } \\
\text { plasms }\end{array}$ \\
\hline Observed deaths & 216 & 459 & 54 & 93 \\
\hline Expected deaths & 308 & 450 & 59 & 82 \\
\hline S.M.R. $\dagger$ & $70 \cdot 1$ & $102 \cdot 0$ & $91 \cdot 5$ & 113.4 \\
\hline
\end{tabular}

*D. D. Reid, 1962, personal communication.

†England and Wales, males $=100$.

91.5) than in underground workers (S.M.R. $=70 \cdot 1$ ) (Table 2). The discrepancy in these data probably arises from the relative inaccuracy which Heasman and his colleagues found in the records of job description used by the Registrar General.

An analysis by Reid of lung cancer death rates in the different divisions of the National Coal Board showed relatively high rates in the north, north-west, north-east, and south-west divisions compared with the rest (Table 3). The high rate in the south-west

TABLE 3

STANDARDIZED MORTALITY RATIOS FOR NEOPLASMS OF LUNG AND ALL NEOPLASMS IN DIVISIONS OF THE NATIONAL COAL BOARD, 1955 (N.C.B. $=100$ )*

\begin{tabular}{l|c|c}
\hline \multicolumn{1}{c|}{ Division } & $\begin{array}{c}\text { Neoplasms of Lung } \\
\text { (S.M.R.) }\end{array}$ & $\begin{array}{c}\text { All Neoplasms } \\
\text { (S.M.R.) }\end{array}$ \\
\cline { 2 - 3 } Durham & 63.2 & 94.9 \\
North-east & 113.3 & 95.3 \\
North-west & 129.6 & 117.1 \\
East Midlands & 82.4 & 89.7 \\
West Midlands & 84.6 & 78.2 \\
South-west & 108.7 & 113.3 \\
Kent & $93.2 \dagger$ & $60.9 \dagger$ \\
North & 147.0 & 128.9 \\
\hline
\end{tabular}

*D. D. Reid, 1962, personal communicaton.

†S.M.R.s based on less than 10 observed deaths.

is in conflict with the findings of Kennaway and Kennaway and of the Registrar General, but a close comparison with the latter's data is not possible because of differences between the regional divisions of the country and those of the National Coal Board.

\section{Mortality in the Rhondda Fach}

Access has been obtained to unpublished data acquired by the Epidemiological Unit of the Medical Research Council (South Wales) during the course of investigations in the Rhondda Fach, a small coalmining valley in Glamorgan (A. L. Cochrane, 1962, personal communication). This community was first surveyed for tuberculosis in 1950-51, when $95 \%$ of all miners and ex-miners were radiographed
(Cochrane, Cox, and Jarman, 1952). Since then the population has been followed and practically all deaths have been traced.

The community which was studied included 5,096 miners and ex-miners aged 35 and over whose death rate from lung cancer during 1951-56 was appreciably lower than the national rate for males, the S.M.R. being 81 . However, the statistical significance of this ratio is limited because it is based on a small number of deaths, the S.M.R. being less than twice its standard error.* An analysis of deaths according to the radiographic category of pneumoconiosis showed the lowest mortality from lung cancer in miners with simple pneumoconiosis, an intermediate rate in those with no evidence of pneumoconiosis, and the highest rate, equal to the national average, among men with progressive massive fibrosis (Table 4).

\section{TABLE 4}

STANDARDIZED MORTALITY RATIOS FOR NEOPLASM OF THE LUNG AND BRONCHUS OF MEN AGED 35 AND OVER FROM THE RHONDDA FACH, 1951-56 (England and Wales, males $=100$ )

\begin{tabular}{|c|c|c|c|}
\hline & $\begin{array}{c}\text { Expected } \\
\text { Deaths }\end{array}$ & $\begin{array}{c}\text { Observed } \\
\text { Deaths }\end{array}$ & S.M.R.* \\
\hline $\begin{array}{l}\text { Miners and ex-miners } \\
\text { Non-miners }\end{array}$ & $\begin{array}{r}36.975 \\
5.650\end{array}$ & $\begin{array}{r}30 \\
3\end{array}$ & $\begin{array}{l}81 \cdot 1 \\
53 \cdot 1 *\end{array}$ \\
\hline $\begin{array}{l}\text { Radiographic category of } \\
\text { pneumoconiosis } \\
0 \\
\text { 1,2, and } 3 \\
\text { P.M.F. }\end{array}$ & $\begin{array}{r}18.419 \\
10.506 \\
8.050\end{array}$ & $\begin{array}{r}16 \\
6 \\
8\end{array}$ & $\begin{array}{l}86.9 \\
57.1 \\
99.9\end{array}$ \\
\hline
\end{tabular}

*Based on less than five deaths.

\section{Mortality in Mining and Non-mining Towns}

An indirect guide to the relative lung cancer mortality of miners is provided by a comparison of death rates in towns which are situated in mining and non-mining areas. Mortality data have been extracted from the Registrar General's Quarterly Returns for 11 towns in Wales during 1956-61. To reduce the bias arising from differences in age and sex structure between the different populations, each crude death rate has been multiplied by the appropriate Area Comparability Factor. This factor relates to deaths from all causes, so that its applicability is limited by any difference in age pattern between lung cancer deaths and deaths from all causes.

The death rates are seen to be lower in the towns situated in mining areas than in those in non-mining areas (Table 5). This trend may partly be associated with the greater population of several of the nonmining towns, for there is an established correlation

\footnotetext{
*Where S.E. $=100 \sqrt{\frac{R}{S}}$, if $R$ is the observed number of deaths and $S$ is the expected number.
} 
TABLE 5

MORTALITY FROM LUNG CANCER IN SELECTED TOWNS IN WALES

Calculated from the Registrar General's Quarterly Returns for England and Wales, 1959-62

\begin{tabular}{|c|c|c|c|c|}
\hline Town & $\begin{array}{c}\text { Average } \\
\text { Popula- } \\
\text { tion } \\
1956-61\end{array}$ & $\begin{array}{c}\text { Average } \\
\text { Annual } \\
\text { Death } \\
\text { Rate from } \\
\text { Lung } \\
\text { Cancer } \\
\text { per 1,000 } \\
\text { Popula- } \\
\text { tion }\end{array}$ & $\begin{array}{c}\text { Area } \\
\text { Compara- } \\
\text { bility } \\
\text { Factor* }\end{array}$ & $\begin{array}{c}\text { Corrected } \\
\text { Annual } \\
\text { Death } \\
\text { Rate } \\
\text { per } 1,000 \\
\text { Popula- } \\
\text { tion }\end{array}$ \\
\hline $\begin{array}{l}\text { Mining Areas } \\
\text { Ebbw Vale } \\
\text { Pontypridd } \\
\text { Caerphilly } \\
\text { Aberdare } \\
\text { Merthyr Tydfil } \\
\text { Rhondda }\end{array}$ & $\begin{array}{r}28,332 \\
37,003 \\
37,293 \\
39,705 \\
59,238 \\
105,110\end{array}$ & $\begin{array}{l}0 \cdot 294 \\
0 \cdot 338 \\
0 \cdot 259 \\
0 \cdot 248 \\
0 \cdot 414 \\
0 \cdot 282\end{array}$ & $\begin{array}{l}1 \cdot 23 \\
1.04 \\
1 \cdot 30 \\
1.02 \\
1.08 \\
1 \cdot 16\end{array}$ & $\begin{array}{l}0.362 \\
0.352 \\
0.337 \\
0.253 \\
0.447 \\
0.327\end{array}$ \\
\hline $\begin{array}{l}\text { Non-mining Areas } \\
\text { Wrexham } \\
\text { Barry } \\
\text { Newport } \\
\text { Swansea } \\
\text { Cardiff }\end{array}$ & $\begin{array}{r}33,043 \\
42,130 \\
105,077 \\
164,075 \\
253,495\end{array}$ & $\begin{array}{l}0.424 \\
0.392 \\
0.452 \\
0.475 \\
0.427\end{array}$ & $\begin{array}{l}1 \cdot 16 \\
1 \cdot 10 \\
1 \cdot 18 \\
1 \cdot 10 \\
1 \cdot 11\end{array}$ & $\begin{array}{l}0.492 \\
0.431 \\
0.533 \\
0.522 \\
0.474\end{array}$ \\
\hline
\end{tabular}

${ }^{*}$ England and Wales $=1.00$.

between lung cancer mortality and urban population density (Stocks, 1952). However this factor will not account for all the differences, particularly the high death rates in Wrexham, Barry, and Newport compared with those in the mining towns of similar size. This low mortality from lung cancer in mining towns, if representative of the country as a whole, would be in keeping with the low mortality recorded for miners.

\section{Discussion}

Limitations of Occupational Mortality Data.Mortality statistics and necropsy data have been presented from various sources and suggest that death from lung cancer is relatively infrequent among coal-miners. The least satisfactory of this evidence is that derived from necropsy material, for the many factors which influence the selection of deaths for necropsy render them unrepresentative of deaths in the population from which they are drawn. Thus the necropsy incidence of lung cancer in miners should be compared with that in non-miners who are alike in all respects except occupation. Such a comparison was made by James but not by the other pathologists whose papers have been quoted.

A special necropsy selection factor operates for coal-miners which arises from the award of an industrial pension to relatives of the deceased if it can be shown that pulmonary tuberculosis or pneumoconiosis contributed to death. For this reason a large proportion of miners' deaths are submitted to necropsy, especially when pulmonary symptoms have been prominent, and incidentally this will in- clude a large proportion of all deaths from pulmonary cancer. This selection factor is not applicable to non-miners, in whom, therefore, a lower proportion of all lung cancer deaths come to necropsy. Allowance for this bias increases the significance of the finding by James that lung cancer was less frequent at necropsies on miners than on non-miners.

Coal-miners have a higher overall death rate than the general male population, largely because of deaths from industrial accidents and pneumoconiosis, so that fewer would be expected to survive to the age at which the risk of developing lung cancer becomes greatest. Thus, other factors being equal, their mortality from this disease will inevitably be reduced. Although this effect of competing causes of death influences necropsy data and crude death rates, it is largely eliminated by the use of the standardized mortality ratio (Case, 1958), the index of occupational mortality favoured by the Registrar General and most other workers in this field.

However, the occupational mortality statistics of the Registrar General are subject to other sources of inaccuracy. One of the main deficiencies arises from the system of occupational classification, which is according to the last job of the deceased. This takes no account of previous occupations or duration of employment, although such information may be highly relevant to the cause of death. For example, in the last Decennial Supplement on occupational mortality deaths from pneumoconiosis were recorded for men whose registered occupations involved no dust exposure, such as publicans, costermongers, and company directors (Registrar General, 1958). Clearly, analysis by this method must carry a limited sensitivity to real occupational mortality differences.

These criticisms are much less applicable to the mortality data acquired from the Rhondda Fach, where the majority of miners and ex-miners have worked in the pits for many years, in the absence of alternative opportunities for employment. In addition those classified as ex-miners include those who subsequently took up other jobs. Yet the S.M.R. for lung cancer in miners from this valley is similar to that reported by the Registrar General, which suggests that the latter's figures are not merely a result of the bias of classification according to the last occupation of the deceased.

Another source of inaccuracy arises from errors in statement of employment occurring in documents which are used by the Registrar General for the calculation of occupational mortality. Heasman and colleagues investigated this problem and found that these errors occurred more frequently at death certification than on census schedules and were such as 
falsely to elevate the recorded death rates of coalminers compared with those of other men (Heasman et al., 1958). Allowance for this factor increases the significance of the low rates for lung cancer in miners recorded by the Registrar General and by Kennaway and Kennaway.

Perhaps the most important source of inaccuracy in cancer mortality statistics arises from errors of clinical diagnosis and hence of certification of the cause of death. There is reason to suppose that diagnostic errors are particularly frequent among coal-miners, in whom the detection of lung cancer in the presence of pneumoconiosis presents special difficulties. If uncorrected, these errors would falsely lower the miners' recorded mortality from lung cancer. However, this special tendency towards clinical underdiagnosis is balanced by the previously mentioned high proportion of miners' deaths that are submitted to necropsy, where errors of diagnosis are mainly corrected. For instance in only $19 \%$ of registered male lung cancer deaths in England and Wales in 1960 was the cause confirmed by previous operation or by necropsy (Registrar General, 1962), whereas in the Rhondda Fach during 1950-59 65\% of such deaths in miners and ex-miners were confirmed at necropsy (A. L. Cochrane, 1963, personal communication). As a result of this high necropsy rate it seems likely that the proportion of deaths from lung cancer which are wrongly certified as to cause is no higher for coal-miners than for other men, and therefore their low recorded mortality is probably not a consequence of diagnostic error.

After the various inaccuracies of compilation and interpretation of occupational mortality data have been considered the evidence for a low mortality from lung cancer among coal-miners remains convincing. The question then arises whether this occupational trend is explicable by factors which are known to influence the prevalence of the disease in the general population.

Factors Determining the Incidence of Lung Cancer among Coal-miners.-Cigarette smoking is widely accepted as the most important single factor in determining the general incidence of lung cancer. It is therefore necessary to enquire whether the average tobacco consumption of coal-miners is unusually low.

In 1948 the Pneumoconiosis Research Unit (M.R.C., South Wales) studied the mining community of Whitehaven, Cumberland and found that $83 \%$ of miners were smokers compared with $81 \%$ of the general male population of similar age as reported in a current national survey by the Hulton Press (A. L. Cochrane, 1962, personal communication). In a later investigation in Leigh, Lancashire
$87.9 \%$ of a random sample of coal-miners were found to be smokers compared with $85.7 \%$ of nonminers, and the quantity of tobacco smoked was similar in both groups (Higgins, Oldham, Cochrane, and Gilson, 1956).

An analysis of the current smoking habits of over 10,000 adults in the midlands according to occupation showed the highest proportion of cigarette smokers, namely $69 \%$, among miners and pottery workers, the proportions in other trades varying between $63 \%$ and $49 \%$ (Cross, McDowell, and Posner, 1958). In the Rhondda Fach it was found that $94.5 \%$ of 300 miners and ex-miners were current smokers compared with $87.4 \%$ of 300 non-miners of similar age, but that $37 \%$ of the latter smoked heavily compared with $30 \%$ of the former (Higgins and Cochrane, 1961), and the same trend was found in over 4,000 Scottish miners whose smoking habits were compared with the national average for males (Ashford, Brown, Duffield, Smith, and Fay, 1961).

Todd (1959) surveyed the smoking habits of quota samples of the population in the United Kingdom and reported that in 1952-3 the average daily consumption of miners and quarrymen was 13.3 cigarettes or their equivalent, whereas the national daily average for men of the same age was $12 \cdot 5$. A later report (Todd, 1962) stated that $65.9 \%$ of mineworkers in 1958 smoked manufactured cigarettes at an average rate of $145 \frac{1}{2}$ a week compared with $58 \%$ of men from all social classes who smoked an average of 130 a week; whereas in 1961 the position was reversed and $52.5 \%$ of miners smoked an average of $104 \frac{1}{2}$ cigarettes a week compared with $58.6 \%$ of all men who smoked 131 a week.

Brown (1962) reported the findings of the Pneumoconiosis Field Research (National Coal Board) from six collieries in England, Scotland, and Wales, which showed a higher proportion of cigarette smokers among miners ir each age group than the national average as reported by Todd. She also quoted the results of a New Zealand survey (de Hamel, 1961) in which there was a similarly higher proportion of smokers among miners; those aged 15-34 and 55-64 smoked more heavily than the nonminers, but for ages 35-54 the position was reversed.

A recent investigation into the length of cigaretteends that miners discard unsmoked showed that among 1,250 miners and ex-miners aged 35-64 the mean length of cigarette butt was $20.1 \mathrm{~mm}$. (I. T. T. Higgins, 1962, personal communication). This is similar to that reported by Doll, Hill, Gray, and Parr (1959) for a random sample of male smokers aged 21 and over, namely $19.3 \mathrm{~mm}$., and to that reported by Todd (1963) for men aged 40-69, namely $21 \mathrm{~mm}$.

Summarizing these data, numerous investigators 
have found little difference in smoking habits between coal-miners and other men. The recorded trend is towards a slightly higher proportion of cigarette smokers among miners, although some authors have reported a slightly higher proportion of heavy smokers among non-miners. Clearly the evidence does not suggest that the low incidence of lung cancer among coal-miners results from unusually low cigarette consumption. This conclusion is supported by an analysis of the past and present smoking habits of 746 patients with lung cancer who attended Sully Hospital, Glamorgan, during 1954-60, a series which included 172 coal-miners and exminers. Similar proportions of smokers were recorded among miners $(96.2 \%)$ and non-miners $(97.4 \%)$, compared with a much lower proportion among female patients $(63 \cdot 4 \%)$.

Other than cigarette smoking, the factor that is widely suspected to confer an increased risk of developing lung cancer is exposure to atmospheric pollution of the type which prevails in large industrial towns. It is difficult to generalize about the levels of such air pollution to which miners are exposed, for mining communities are widely distributed in many different parts of the country. However, it is possible that the areas in which coal-miners live and work are in general relatively free from industrial atmospheric pollution. If this factor were important one would expect a low mortality from lung cancer among miners' wives as well as among miners, for other than coal-dust both groups are subjected to similar atmospheric conditions. In fact the S.M.R. of miners' wives for cancer of the lung in 1949-53 was 85 , which although below the national rate for women is still significantly higher than the corresponding S.M.R. for coal-miners (the difference between the two S.M.R.s is greater than twice its standard error).*

There remains the possibility that a reduced risk of acquiring lung cancer is a specific effect of working in a coal-mine and that an occupational factor such as the inhalation of coal-dust antagonizes the induction of pulmonary malignant change. If so, one would expect this effect to be quantitatively related to dust exposure, and some of the data which have been quoted appear to support this. Thus Reid found a lower mortality from lung cancer among underground workers than surface workers, Kennaway and Kennaway demonstrated a particularly low mortality from lung cancer in the coal-field where pneumoconiosis is most prevalent, and James reported the lowest incidence of lung cancer at necropsy on miners with complicated pneumoconiosis.

\footnotetext{
*Where S.E. $=\sqrt{\frac{(\text { first S.M.R.) }}{\text { R }_{1}}+\frac{(\text { second S.M.R.) }}{R_{2}}}$ if the two S.M.R.s are based on $R_{1}$ deaths and $R_{2}$ deaths respectively.
}

However, contradictory findings have been recorded by other investigators, so that further studies are necessary before valid conclusions can be drawn. Of particular value would be a large-scale investigation of the mortality of miners from lung cancer analysed according to the category of pneumoconiosis.

I wish to thank Professor A. L. Cochrane, Director of the Epidemiological Unit, Medical Research Council (South Wales), for his help with this work and for generously granting access to information about mortality from lung cancer in the Rhondda Fach. I am also grateful to Professor D. D. Reid for permission to quote from his study of the mortality of miners employed by the National Coal Board. My thanks are due to Dr. H. Campbell and to Dr. R. A. M. Case for statistical advice; to Dr. W. R. L. James for a helpful discussion about necropsy material; to Dr. J. M. Rogan, Chief Medical Officer, National Coal Board, for permission to quote from a confidential document of the Pneumoconiosis Field Research, National Coal Board; and to Miss G. Sweet for secretarial help.

\section{REFERENCES}

Ashford, J. R., Brown, S., Duffield, D. P., Smith, C. S., and Fay, J. W. J.'(1961). Brit. J. prev. soc. Med., 15, 106.

Brown, S. (1962). Ref. No. S.C. 849/MR/41. National Coal Board Scientific Dept, London.

Case, R. A. M. (1958). In Carcinoma of the Lung, edited by J. R. Bignall, p. 270. Livingstone, Edinburgh and London.

Chatgidakis, C. B. (1963). Brit. J. industr. Med., 20, 236.

Cochrane, A. L., Cox, J. G., and Jarman, T. F. (1952). Brit. med. J., $2,843$.

Cross, K. W., McDowell, L. A., and Posner, E. (1958). Ibid., 1, 862. Doll, R. (1953). Ibid., 2, 521.

- (1958). Brit. J. industr. Med., 15, 217

Hill, A. B., Gray, P. G., and Parr, E. A. (1959). Brit. med. J., 1,322 .

Gooding, C. G. (1946). Lancet, 2, 891

de Hamel, F. A. (1961). The Grey Valley Survey. Spec. Rep. No. 3. Dept of Health, Wellington, New Zealand.

Heasman, M. A., Liddell, F. D. K., and Reid, D. D. (1958). Brit. J. industr. Med., 15, 141 .

Higgins, I. T. T., and Cochrane, A. L. (1961). Ibid., 18, 93.

Oldham, P. D., Cochrane, A. L., and Gilson, J. C. (1956). Brit. med. J., 2, 904

James, W. R. L. (1955). Brit. J. industr. Med., 12, 87.

Kennaway, N. M., and Kennaway, E. L. (1936). J. Hyg. (Lond.), 36, 236 .

(1947). Brit. J. Cancer, 1, 260.

- (1947). Brit. J. Caid., 7, 10 .

McVittie, J. C. (1949). 'Postgrad. med. J., 25, 618

Registrar General's Decennial Supplement, England and Wales, 1931. Part IIa. Occupational Mortality, p. 221. (1938). H.M.S.O., London.

Registrar General's Decennial Supplement, England and Wales, 1951. Part II, Vol. 1, Occupational Mortality, pp. 9, 18, 35 and 96. (1958). H.M.S.O., London.

Registrar-General's Quarterly Return for England and Wales, Nos. $441,445,449$ and 453, Appendices A, B and C. (1959-62). $441,445,449$ and 453.
H.M.S.O., London.

Registrar General (1962). Statistical Review of England and Wales, 1960. Part III, p. 108. H.M.S.O., London.

Registrar-General for Scotland (1956). Annual Report for 1955, No. 101. H.M.S.O., London.

Stocks, P. (1952). Brit. J. Cancer, 6, 99.

Todd, G. F. (1959). Statistics of Smoking. Research Papers No. 1, 2nd ed. Tobacco Manufacturers' Standing Committee, London. (1962). Statistics of Smoking. Research Papers No. 1, 3rd ed. Tobacco Manufacturers' Standing Committee, London. Tobacco Manufacturers' Standing Committee, London.
(1963). Cigarette Smoking Characteristics in the U.K., South Africa and Australia. Research Papers No. 5, p. 6. Tobacco Africa and Australia. Research Council, London. 